\title{
Supramolecular nano-fibrous peptide/polymer hydrogels for the multiplexing of bioactive signals
}

Elham Radvar and Helena S. Azevedo*

School of Engineering and Materials Science, Institute of Bioengineering, Queen Mary

University of London, Mile End Road, London, United Kingdom.

E-mail: h.azevedo@qmul.ac.uk 


\section{ABSTRACT}

The ability to provide multiple functions within a single scaffold biomaterial is a major goal in tissue engineering. Self-assembling peptide-based hydrogels are gaining significant attention as three-dimensional biomaterials because they provide a network of nanofibers similar to the native extracellular matrix while allowing the presentation of multiple biochemical cues for cell signalling. Herein, we combine a positively charged peptide amphiphile (PA) and the negatively charged synthetic polymer poly(sodium 4-styrenesulfonate) (PSS) to fabricate hybrid hydrogels through supramolecular self-assembly. PSS/PA hydrogels show rather high mechanical stiffness while being stable in buffered environment. The sulfonate functionality in PSS promotes hydrogel mineralization which can be controlled if undertaken in standard osteogenic medium. Loading proteins with different charges in the hydrogels reveals their ability to retain and sustain their release and indicates their potential for the controlled delivery of growth factors. Human mesenchymal stem cells encapsulated in PSS/PA hydrogels remain viable. The biomimetic nanofibrous structure of the hydrogels, together with multiplexing of bioactive signals, can provide a suitable environment for stem cell differentiation.

Key words: Supramolecular hydrogels, nanofibers, bioactive signals, biomimetic mineralization, protein delivery, 3D stem cell culture 


\section{Introduction}

The extracellular matrix (ECM) of tissues serves multiple roles to ensure tissue homeostasis, from providing anchorage sites for cell adhesion and migration to regulating the availability of soluble growth factors (GFs) for cell proliferation and differentiation. Mimicking the multifunction features of the native ECM has been a major goal when designing biomaterials for tissue engineering and regenerative medicine. In the recapitulation of the ECM, several methods have been pursued, from macromolecular crowding and self-assembly to electrospinning and patterning. For example, to replicate the ECM biophysical properties, the typical nanofibrillar collagen network, electrospinning ${ }^{1}$ and self-assembly ${ }^{2}$ have been used. However, electrospinning uses polymer solutions dissolved in non-aqueous solvents and an electric field to produce nanofibers. These harsh conditions unable the incorporation of cells during nanofiber processing. In contrast, self-assembly can occur at physiological conditions generating nanofibers with diameters as small as $10 \mathrm{~nm}$ and smaller than those obtained by electrospinning. In addition, selfassembled peptide nanofibers can be designed to contain sequences derived from ECM proteins $^{3,4}$ further extending the ability of mimicking ECM biochemical properties. The ability of the ECM to regulate the activity of GFs results from the supramolecular binding of GFs to insoluble ECM components, notably to heparan sulfate proteoglycans via electrostatic interactions. ${ }^{5}$ Several creative approaches have been reported to emulate the GF binding to sulfated glycosaminoglycans (GAGs) in native ECMs, including sulfation of polysaccharides ${ }^{6-8}$; incorporation of heparin through covalent bonds $^{9}$ or supramolecular interactions using specific ${ }^{10}$ or non-specific ${ }^{11,12}$ peptide sequences and in polyelectrolyte complexes ${ }^{13,14}$; synthesis of heparin-

like molecules ${ }^{15,16}$ (e.g. sulfonated peptides). From these studies, it becomes obvious that selfassembling peptides can provide much of the ECM functionality (cell adhesion motifs such as 
RGD, sulfonated groups, nanofibrillar structure). Peptides can also be combined with (bio)polymers to self-assemble into multicomponent hydrogels, either through the formation of covalent linkages or non-covalent interactions. ${ }^{17}$

Herein, we used self-assembly to prepare multi-functional hydrogels through electrostatic interactions between a positively charged peptide amphiplile (PA) and a negatively charged synthetic polymer bearing sulfonate functionality, poly(sodium 4-styrenesulfonate) (PSS) (Figure 1-A). Previous studies showed that sulfonate groups can promote the nucleation of calcium ions ${ }^{18,19}$ and we have thus exploited PSS-induced hydroxyapatite mineralization in this hydrogel system. The negative sulfonate groups in PSS can also provide binding sites for basic proteins, similar to sulfated glycosaminoglycans. The dual functionality of PSS has been utilized in combination with PAs of opposite charge to form self-assembled nanofibrous hydrogels. We show that these hydrogels are able to mineralize in cell culture conditions, control the release of positively charged proteins and support the viability and spreading of stem cells.

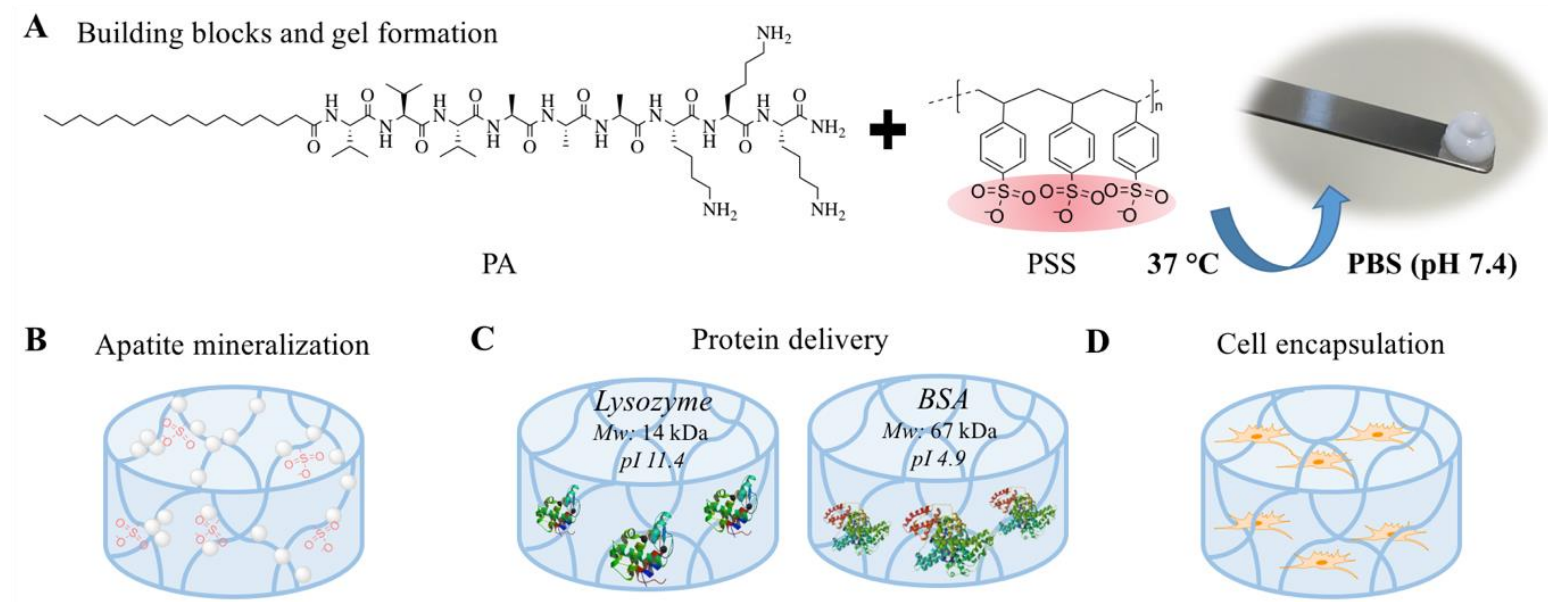

Figure 1. Self-assembling nano-fibrous hydrogels for the multiplexing of bioactive signals. (A) Selfassembly of peptide amphiphile (PA) and PSS forming a self-supporting hydrogel; (B) Calcium phosphate mineral nucleation on the hydrogel's nanofibrous structure; Hydrogel can be used as a scaffold for protein delivery (C) and 3D cell encapsulation (D). 


\section{Experimental Section}

\section{Materials and methods}

Materials. Fmoc-protected amino acids, Fmoc-Ala-OH, Fmoc-Lys(Boc)-OH, Fmoc-Val-OH, Fmoc-Arg(Pbf)-OH, Fmoc-Gly-OH, Fmoc-Asp(OtBu)-OH, Fmoc-Ser(Tbu)-OH and 4methylbenzhydrylamine (MBHA) rink amide resin (100-200 mesh) were purchased from Novabiochem (Merck, UK). Triisopropylsilane (TIS) and piperidine were obtained from Alfa Aesar (UK). Poly(sodium 4-styrenesulfonate) with two different molecular weights (70 kDa and $1 \mathrm{MDa})$ and palmitic acid $\left(\mathrm{C}_{16} \mathrm{H}_{32} \mathrm{O}_{2}\right)$ were obtained from Sigma-Aldrich, UK. Fluorescenttagged bovine serum albumin (BSA-FITC) was acquired from Sigma-Aldrich (UK) and lysozyme labelled with Rhodamine B and FITC (lysozyme-FITC) were obtained from Nanocs (US). Cell culture medium (DMEM), fetal bovine serum (FBS) and penicillin-streptomycin (Pen/Strep) were purchased from Gibco (Thermo Fisher scientific, UK). Other chemicals were purchased from Sigma-Aldrich (UK) unless otherwise stated.

Peptide synthesis and purification. Peptide amphiphiles $\left(\mathrm{C}_{16} \mathrm{~V}_{3} \mathrm{~A}_{3} \mathrm{~K}_{3}\right.$ and $\left.\mathrm{C}_{16} \mathrm{~V}_{3} \mathrm{~A}_{3} \mathrm{~K}_{3} \mathrm{G}_{3} \mathrm{RGDS}\right)$ were synthesized in an automated peptide synthesizer (Liberty Blue, CEM, UK) using standard 9-fluorenylmethoxycarbonyl (Fmoc)-based solid phase synthesis protocol. Peptides were grown on the solid support, MBHA rink amide resin, using (4:4:4) equivalents of Fmoc-protected amino acids, 1-hydroxybenzotriazole hydrate (HOBt, Carbosynth Ltd. UK) and N,N'diisopropylcarbodiimide (DIC, Thermo Fisher, UK) for the coupling reactions. Fmoc group was deprotected using 20\% (v/v) piperidine in dimethylformamide (DMF, VWR, UK). Before cleavage from the resin, the peptide $\mathrm{N}$-terminal was capped with a 16 -carbon alkyl chain $\left(\mathrm{C}_{16}\right.$, palmitic acid) using a similar coupling protocol. The removal of the side-chains protecting 
groups and cleavage of the peptides from the resin was performed with a mixture of trifluoroacetic acid (TFA, Thermo Fisher, UK)/ triisopropylsilane (TIS)/ water (95\%/2.5\%/2.5\% $(\mathrm{v} / \mathrm{v}))$ for 3 hours at room temperature. The peptide solution was collected and reduced down to a viscous solution in a rotary evaporator. Cold diethyl ether was used to precipitate the peptide. After centrifugation, the supernatant was discarded and the solid precipitate allowed to dry overnight. The peptide mass was confirmed by electrospray ionization mass spectrometry (ESIMS) using a single quadrupole mass detector (SQ Detector 2, Waters, UK). A Waters 2545 Binary Gradient high-performance liquid chromatography (HPLC) system with a preparative reverse-phase $\mathrm{C} 18$ column (X-Bridge prep OBD, $5 \mu \mathrm{m}, 30 \times 150 \mathrm{~mm}$ column, Waters, UK) was used for purification of the crude peptides using a water/acetonitrile $(0.1 \%$ TFA $)$ gradient. Fraction collection was made based on the peptide mass and acetonitrile removed by rotary evaporation followed by lyophilisation to obtain the peptide in powder form. Pure peptide amphiphile was treated with hydrochloric acid $(10 \mathrm{mM})$ in three cycles of lyophilization in order to remove the TFA counter ions. Finally, the peptides were dialyzed against ultrapure water using 500 MWCO dialysis membrane (Spectrum Labs, The Netherlands) and lyophilized. Purity of the peptide was confirmed using analytical reverse-phase HPLC (Alliance HPLC system coupled with $2489 \mathrm{UV} /$ Vis detector, Waters, UK). Peptide sample $\left(1 \mathrm{mg} \mathrm{ml}^{-1}\right)$ was injected and run through a C18 column (XBridge analytic $3.5 \mu \mathrm{m}, 4.6 \times 150 \mathrm{~mm}$, Waters, UK) using a gradient of water/acetonitrile $(0.1 \% \mathrm{TFA})$ at $1 \mathrm{ml} / \mathrm{min}$.

Zeta potential. PA and PSS ( $70 \mathrm{kDa}$ and $1 \mathrm{MDa}$ ) solutions were analysed in a Nano-ZS Zetasizer (Malvern Instruments) for measuring their zeta potential. Samples were prepared at $0.05 \mathrm{wt} \%$ in water $(\mathrm{pH} 7)$ and $\mathrm{PBS}(\mathrm{pH} 7.4)$. 
Preparation of PSS/PA hydrogels. PA and PSS solutions were prepared by dissolving the powders in phosphate buffer saline (PBS) to obtain the desired concentration. Hydrogels were produced in a 96 well plate by casting $50 \mu \mathrm{L}$ of a $2 \%(\mathrm{wt} \%)$ PSS (70 $\mathrm{kDa}$ or $1 \mathrm{MDa}$ ) solution followed by $50 \mu \mathrm{L}$ of $2 \%$ (wt $\%$ ) PA solution. Hydrogels were formed after incubation at $37{ }^{\circ} \mathrm{C}$ for 30 minutes.

Oscillatory Rheology. All rheological experiments were performed in a Discovery Hybrid Rheometer (DHR-3, TA Instruments, USA) fitted with a $8 \mathrm{~mm}$ diameter plate geometry (advanced peltier plate, APP). Strain and frequency sweeps were performed on the various hydrogels $(\mathrm{n} \geq 3)$ at $1 \mathrm{~Hz}$ frequency and $0.1 \%$ strain, respectively. Measurements were carried out at $25{ }^{\circ} \mathrm{C}$ with a loading gap height set to $0.5 \mathrm{~mm}$.

Stability of hydrogels. The stability of the PSS/PA hydrogels was studied by incubating them in aqueous conditions (water and PBS buffer $\mathrm{pH} 7.4$ ) at $37^{\circ} \mathrm{C}$. The absorbance of the styrene ring at $260 \mathrm{~nm}$ was used to monitor the release of PSS in the medium over the time (28-days period). PSS concentration was calculated from a calibration curve obtained from PSS standards. Three repeats were performed for each hydrogel condition and time.

Scanning electron microscopy (SEM). The microstructure of the hydrogel surface and crosssection was examined by scanning electron microscopy (SEM). Samples for SEM observation were prepared by incubating the hydrogels in $2 \%$ glutaraldehyde in PBS for 1 hour at $4{ }^{\circ} \mathrm{C}$. After three cycles of washing with phosphate buffer saline (PBS), hydrogels were progressively dehydrated using graded ethanol concentrations. Ethanol removal was performed using a critical point dryer (EMS 850, Electron Microscopy Sciences, USA). Samples were first coated with a gold layer (5-30 nm) using an Emitech SC7620 sputter coater (Quorum Technologies, UK) then 
imaged in a field emission gun scanning electron microscope (FEG SEM, Inspect F50, FEI, Netherlands).

Hydrogels mineralization. The hydrogels were incubated in stimulated body fluid (SBF) solution for 3, 7 and 14 days at $37{ }^{\circ} \mathrm{C}$. The SBF solution contains ion concentrations similar to those of the human blood plasma $\left(\mathrm{Na}^{+} 142.0, \mathrm{~K}^{+} 5.0, \mathrm{Ca}^{2+} 2.5, \mathrm{Mg}^{2+} 1.5, \mathrm{Cl}^{-} 147.8, \mathrm{HCO}_{3}^{-} 4.2\right.$, $\left.\mathrm{HPO}_{4}{ }^{2-} 1.0, \mathrm{SO}_{4}{ }^{-2} 0.5 \mathrm{mM}\right){ }^{20,21} \mathrm{SBF}$ solution was replenished twice a week. After each immersion time, the hydrogels were removed from SBF, washed with distilled water and prepared for SEM observation, as described in prior section. Hydrogels were also tested for their mineralization ability in culture medium with and without osteoinducer agents $(10 \mathrm{mM} \beta$ glycerophosphate, $50 \mu \mathrm{g} \mathrm{m}{ }^{-1}$ 2-Pho2-Phospho-L-ascorbic acid trisodium salt and $10 \mathrm{nM}$ dexamethasone) for 7,14 and 21 days. Samples were also washed with PBS before sample preparation for SEM. To determine the composition of the mineral formed, hydrogels were analysed by SEM (FEG SEM, Inspect F50, FEI, The Netherlands) equipped with energy dispersive electron X-ray (EDX) spectroscopy (Oxford Instruments, UK). For the EDX analysis, carbon coating (carbon thread evaporation) was used and the samples were analysed at $10.0 \mathrm{kV}$ voltage. The atomic percentage of minerals were determined using INCA software (Oxford Instruments, UK).

FTIR spectroscopy. In order to confirm the formation of calcium phosphate minerals on the hydrogels, mineralized hydrogels were burnt at $700{ }^{\circ} \mathrm{C}$ to obtain the powder containing the inorganic component. Then, the IR spectra of mineral powder and dried non-mineralized hydrogels were analysed using Brukler Tensor 27 FTIR spectrometer using an attenuated total reflection (ATR) diamond crystal accessory (Bruker, Germany). The absorbance spectrum was measured in the range of $2000-400 \mathrm{~cm}^{-1}$ by averaging 32 individual scans per sample at a 
resolution of $4 \mathrm{~cm}^{-1}$.

Protein loading and release. Hydrogels were loaded with two labelled model proteins having positive (lysozyme-FITC) and negative (BSA-FITC) charges to examine their release profile over time in physiological conditions. The proteins were loaded in the hydrogels at final concentration of $0.05 \mathrm{mg} \cdot \mathrm{ml}^{-1}$ by first dissolving them in PSS (BSA-FITC) or PA (lysozymeFITC) solutions followed by the formation of the gel as described before. Then the loaded hydrogels were incubated in $1 \mathrm{~mL}$ of PBS $(\mathrm{pH} 7.4)$ at $37^{\circ} \mathrm{C}$ and aliquots $(1 \mathrm{~mL})$ were collected at predetermined time intervals and replaced with fresh PBS $(1 \mathrm{~mL})$. Collected samples were kept frozen until experiment completion and then lyophilized. Release experiments were done in triplicate and the protein concentration was determined by dissolving the lyophilized samples in $200 \mu \mathrm{l}$ of PBS and then measuring the fluorescence intensity at excitation/emission wavelengths of $485 / 520 \mathrm{~nm}$ for both BSA-FITC and lysozyme-FITC and calculating the corresponding concentration from a calibration curve constructed for each labelled protein. The amount of protein loaded in each gel was determined by extracting the protein from the gels through physical/mechanical breakdown of the gels (pipetting and sonication) followed by repeated centrifugation and washings of the gel pellet until no fluorescence was detected in the supernatant. The percentage of protein released at each time point was calculated based on the protein amount loaded in the gel and cumulative release plotted over time. The distribution of proteins in the hydrogels was examined by confocal microscopy (Leica TCS SP2) using $488 \mathrm{~nm}$ and $544 \mathrm{~nm}$ laser beams for BSA-FITC, lysozyme-FITC and lysozyme-Rhodamine, respectively.

Lysozyme activity determination. For determining the activity of released lysozyme from the PSS/PA gels, unlabelled enzyme (from hen egg white, Sigma-Aldrich) was loaded in the 1 MDa PSS/PA gels and release studies were conducted as described above. Aliquots were collected and 
kept frozen until further analysis. Later, samples were first lyophilized and dissolved in $100 \mu \mathrm{l}$ of reaction buffer. Enzyme activity was measured using the EnzChek_Lysozyme Assay Kit (Thermo Fisher Scientific) following the instructions provided by the supplier. The initial activity of the enzyme loaded in the gel was determined for calculating the cumulative lysozyme activity released over time. A control (free enzyme in solution incubated at $37{ }^{\circ} \mathrm{C}$ for different periods of time) was performed in triplicate to estimate the effect of incubation time and temperature on enzyme deactivation.

Cell culture and maintenance. hMSCs (passage number 6, PromoCell GmbH, Germany) were used to assess the ability of PSS/PA gels to support cell viability. Cells were first cultured in 75 $\mathrm{cm}^{2}$ flask at density $3 \times 10^{3}$ cells $\mathrm{cm}^{-2}$ and maintained in culture medium (DMEM, low glucose, GlutaMAX $^{\mathrm{TM}}$ supplement, Gibco, Thermo Fisher, UK) supplemented with $10 \%$ FBS, $1 \%$ Pen/Strep and 0.1\% bFGF (FGF-Basic (AA 10-155) recombinant human protein, Thermo Fisher Scientific, UK). Flasks were incubated at $37^{\circ} \mathrm{C}, 5 \% \mathrm{CO}_{2}$. Medium was refreshed twice a week and cells were trypsinized when reached $80 \%$ confluency.

Cell encapsulation and viability in the hydrogels. Cells were encapsulated in $1 \mathrm{MDa}$ PSS/PA and 1 MDa PSS/PA-RGDS (10\% PA-RGDS) hydrogels using $200 \times 10^{3}$ cells per $100 \mu$ hydrogel by mixing half of the cells with the PSS solution and the other half with PA solution. $1 \mathrm{MDa}$ PSS/PA-RGDS hydrogels were prepared as before where the PA solution contained $10 \%$ of PARGDS and $90 \%$ of standard PA at peptide final concentration of $2 \%$ (wt. $\%$ ). After self-assembly (20 minutes), hydrogels with cells were incubated in culture medium (DMEM supplemented with $10 \%$ FBS and $1 \%$ Pen/Strep) at $37^{\circ} \mathrm{C}, 5 \% \mathrm{CO}_{2}$ for 1 and 3 days. Viability of the cells encapsulated in the hydrogels was analysed using LIVE/DEAD ${ }^{\circledR}$ Viability/Cytotoxicity Kit for mammalian cells (Invitrogen, UK). Briefly, each hydrogel sample was treated with $4 \mu \mathrm{M}$ calcein 
$\mathrm{AM}$ and $2 \mu \mathrm{M}$ ethidium homodimer-1 and incubated for 15-20 minutes at room temperature. Hydrogels were imaged using confocal microscopy (Leica TCS SP2) and images were analysed in Image $\mathrm{J}$ for counting the number of live and dead cells. Three hydrogel replicates were used and compared to cell culture as monolayers (control). Statistical differences in viability data were obtained with GraphPad Prism 7 software (USA) using a two-way analysis of variance (ANOVA) with a Bonferroni's multiple comparison test $\left({ }^{*} \mathrm{p}<0.05 ; *^{*} \mathrm{p}<0.01 ; * * * \mathrm{p}<0.001\right.$; NS: not significant).

Scanning electron microscopy of cell-encapsulated hydrogels. The interaction of MSCs with hydrogel's nanofibers was analysed by SEM. MSCs encapsulated in the hydrogels were prepared for SEM as above. The samples were coated with gold layer before observation. 


\section{Results and discussion}

\section{Mechanical properties and stability of self-assembled PSS/PA hydrogels. Peptide}

amphiphiles (PAs) designed by Stupp's laboratory are known to self-assemble into cylindrical nanofibers maintained by strong $\beta$-sheet secondary structures. These PAs are charged molecules that upon mixing with electrolytes or polymers of opposite charge are able to form hydrogels ${ }^{10}$, membranes $^{22}$ or capsules ${ }^{23}$. The self-assembly of PAs with high molecular weight (HMw) polysaccharides, such as hyaluronic acid $(\mathrm{HA})^{24}$, alginate $^{22}$ and $\lambda$-carrageenan ${ }^{22}$ results in the formation of solid membranes at liquid-liquid interface either in the form of a $\mathrm{sac}^{25}$ or planar membrane ${ }^{24}$. However, the use of HMw synthetic polymers has not been fully exploited. Following a similar approach, we combined the positively charged PA (Figure 1A), containing an alkyl chain $\left(\mathrm{C}_{16}\right)$, a $\beta$-sheet forming segment $\left(\mathrm{V}_{3} \mathrm{~A}_{3}\right)$ and three lysine residues $\left(\mathrm{K}_{3}\right)$ with negatively charged poly(sodium 4-styrenesulfonate) (PSS). Contrary to the HA/PA selfassembling systems, or with other polysaccharides, mixing PA with PSS of different Mw (70 $\mathrm{kDa}$ and $1 \mathrm{MDa}$ ) resulted in the formation of self-supporting opaque hydrogels (Figure 1A). It was shown previously that polyelectrolytes with different charge density interact differently with positively charged PAs affecting the micro- and nanostructure of the resulting membrane. ${ }^{22}$ PSS is a strong polyelectrolyte showing a zeta potential $(\zeta)$ of $-49.62 \pm 2.55 \mathrm{mV}$ in water at $\mathrm{pH} 7$ (Figure S2). Viscosity measurements of PSS solution (1 wt $\%, 1 \mathrm{MDa})$ revealed perfect Newtonian behaviour with constant viscosity in a wide shear range and low viscosity close to water $(0.003 \mathrm{~Pa} \cdot \mathrm{s})$ at $37{ }^{\circ} \mathrm{C}$ and shear rate of $70 \mathrm{~s}^{-1}$. In contrast, HA solutions of same concentration and similar molecular weight (1.5 MDa) showed higher viscosity $(0.682 \mathrm{~Pa} \cdot \mathrm{s})$ and shear-thinning behaviour. Because fluid flow is highly dependent on the viscosity, one should expect rapid mixing of PSS and PA solutions leading to PA self-assembly into a random network 
of nanofibers and formation of gel, without the creation of a diffusion barrier as seen in the HA/PA system. The low viscosity of PSS solutions (5 wt $\%, 126.7 \mathrm{kDa})$ was also observed in other studies with SAXS patterns showing characteristic behaviour of salt-free polyelectrolyte solutions and correlation lengths (calculated from $q_{\max }$ ) between 8 and $70 \mathrm{~nm}$ depending on the PSS concentration (from 8.7 to $0.6 \mathrm{wt} \%$, respectively). ${ }^{26}$ While the viscosity of polymer solutions depends mainly on the polymer molecular weight and concentration, intra- and interhydrogen bonding formed between polar hydroxyl groups also play a role in determining the final viscosity, and the extent of hydrogen bonding decreases with increasing temperature and addition of electrolytes into the solution. This is the case in HA molecules, where carboxylate, acetamido and hydroxyl groups enable the formation of intra hydrogen bonds and results in increased viscosity at neutral $\mathrm{pH} \cdot{ }^{27}$

Hydrogels were formed by mixing the PA and PSS solutions at the same volume ratio. However, we have first optimized the hydrogel formulation by testing different PA and PSS concentrations followed by rheological analysis. The rheology data showed changes in the storage modulus with peptide and polymer concentration (Figure S3). However, after incubation in culture medium (DMEM) for 7 days, hydrogels showed different behaviours. Formulations with higher concentrations of PSS made the DMEM environment acidic (as detected by colour change of the medium) and the hydrogels with lower concentration of PSS were unstable. Therefore, formulations of similar concentration of peptide and PSS were used for subsequent experiments. PA solution of $2 \mathrm{wt} \%$ was combined with PSS solution of the same concentration and allowed to self-assemble for 10 minutes. PSS of different Mw (1 MDa and $70 \mathrm{kDa})$ were used to investigate the effect of the polymer length on the assembly and mechanical properties of the hydrogel.

Rheology measurements were carried out first by subjecting the hydrogels to an amplitude sweep 
in a shear strain ranging from $0.01 \%$ to $10 \%$ at constant frequency of $1 \mathrm{~Hz}$. In all tested hydrogels, the storage modulus exceeded the loss modulus, which is a typical behaviour of hydrogel systems and both types of hydrogel (1 MDa PSS/PA and $70 \mathrm{kDa}$ PSS/PA) lost their linearity over strain of 1\% (Figure 2-A,B). ${ }^{28}$ Following the linear viscoelastic region (LVER), strain of $0.1 \%$ was used in frequency sweep measurements.
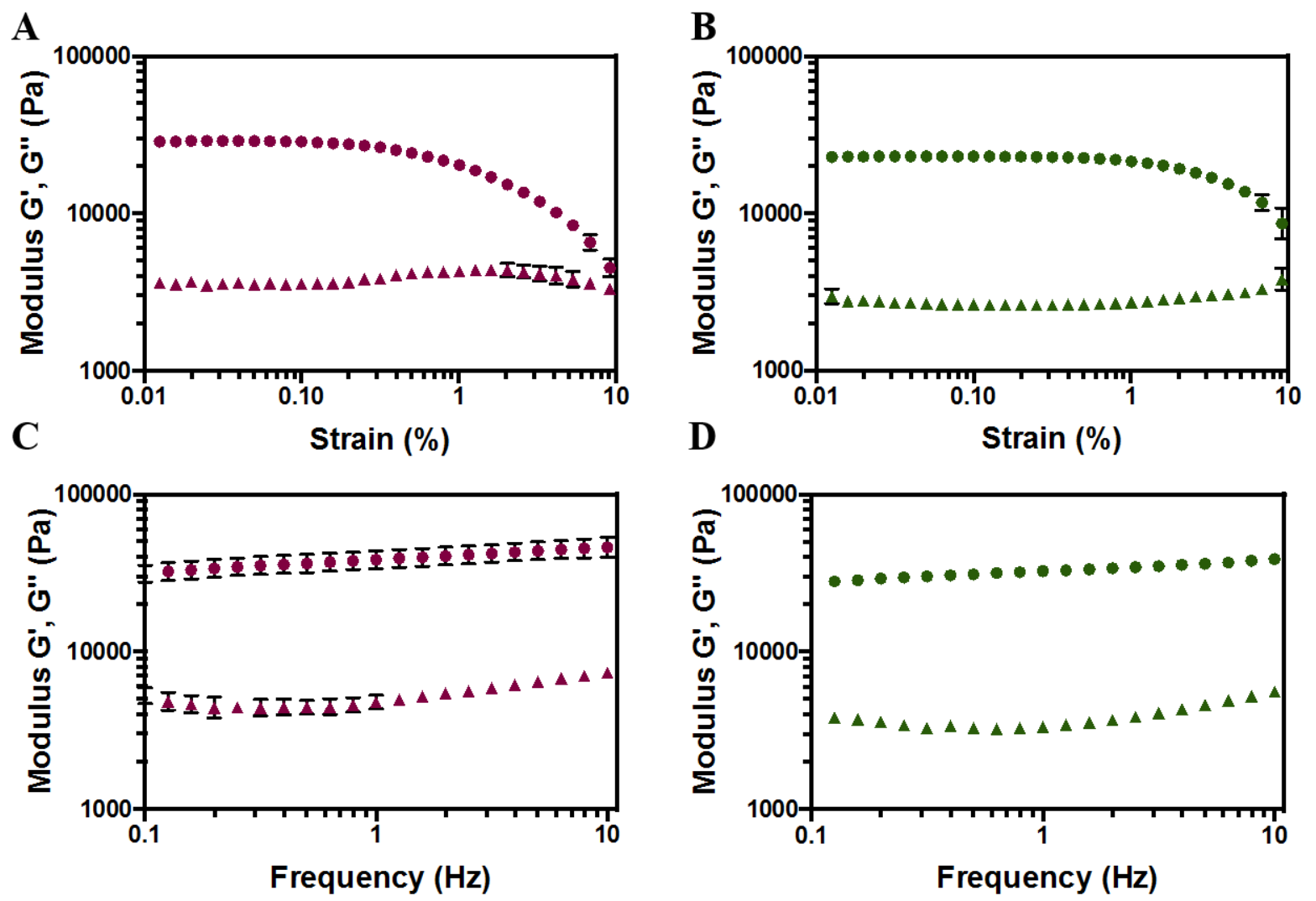

Figure 2. Rheological characterization of PSS/PA hydrogels measured at $25{ }^{\circ} \mathrm{C}$. Amplitude (A, B) and frequency $(\mathrm{C}, \mathrm{D})$ sweep graphs of $1 \mathrm{MDa} \mathrm{PSS} / \mathrm{PA}(\mathrm{A}, \mathrm{C})$ and $70 \mathrm{kDa} \mathrm{PSS} / \mathrm{PA}(\mathrm{B}, \mathrm{D})$; circles refer to storage modulus $\left(G^{\prime}\right)$ and triangles refer to loss modulus $\left(G^{\prime \prime}\right)$.

To measure the stiffness of the hydrogels, frequency sweeps were conducted at $0.1 \%$ strain over a range of frequencies. The storage modulus for both $1 \mathrm{MDa}$ PSS/PA and $70 \mathrm{kDa}$ PSS/PA 
hydrogels is dominant over the loss modulus indicating an elastic rather viscous material. ${ }^{28,29}$ Moreover, the $\tan (\delta)\left(G^{\prime} / G^{\prime}\right)$ variation with frequency showed values below $1(\tan (\delta)<1)$, indicative of a gel system with $G^{\prime}$ always exceeding the $G "{ }^{29} \operatorname{Tan}(\delta)$ is constant across a frequency range 1-10 Hz (Figure S4). A frequency of $20 \mathrm{~Hz}$ was reported for optimal osteoblast proliferation ${ }^{30}$. Both $1 \mathrm{MDa}$ PSS/PA and $70 \mathrm{kDa}$ PSS/PA hydrogels show frequency-independent behavior at frequency range $1-10 \mathrm{~Hz}$ and they are considered as stiff hydrogels $(30-40 \mathrm{kPa})^{31,32}$ (Figure 2-C,D). Different variations of PA hydrogels, formed in the presence of electrolytes, have a stiffness in the range of $20 \mathrm{~Pa}-83 \mathrm{kPa}$ depending on their molecular structure and concentrations $^{28,33,34}$. To increase the stiffness of self-assembling peptide gels, several approaches have been attempted by combining with either peptides or polymers of opposite charge). ${ }^{17,31}$ For example, different types of self-assembling peptides have been combined with sulfated polysaccharides, including heparin ${ }^{10,12,35}$, chondroitin sulfate ${ }^{36}$ and fucoidan ${ }^{37}$, to obtain gels with increased mechanical strength compared to gels crosslinked with multivalent ions. However, the storage modulus obtained did not exceed $50 \mathrm{kPa}$, whereas the mechanical properties of PSS/PA hydrogels can be in the range of $200 \mathrm{~Pa}-200 \mathrm{kPa}$ (Figure S3).

To investigate the stability of the PSS/PA hydrogels in aqueous environments of different ionic strength, they were incubated either in water or phosphate buffered saline (PBS) over a period of 28 days. The stability was assessed by monitoring the release of PSS into the medium. $1 \mathrm{MDa}$ PSS forms more stable hydrogels compared to the lower Mw PSS. As seen in Figure 3-A, the 70 $\mathrm{kDa}$ PSS/PA hydrogels dis-integrated by day 7 in PBS. Moreover, the amount of PSS released to the medium was minimal for both hydrogels over 28 days incubation period (Figure 3-B).

The differences in stiffness and stability of the hydrogels can be explained through the PSS Mw (chain length) and the number of sulfonate groups available for interacting with the PA. The 
higher stability of $1 \mathrm{MDa}$ PSS/PA gels can be due to higher number of sulfonate groups (also confirmed by mapping analysis of the hydrogels (Figure S5) available for interaction with PA fibers leading to a robust intertwined network. However, in the lower Mw PSS/PA gels (70 kDa PSS/PA), the shorter chain length (hence less sulfonate groups) resulted in a less entangled network leading to decreased stability.

A

B

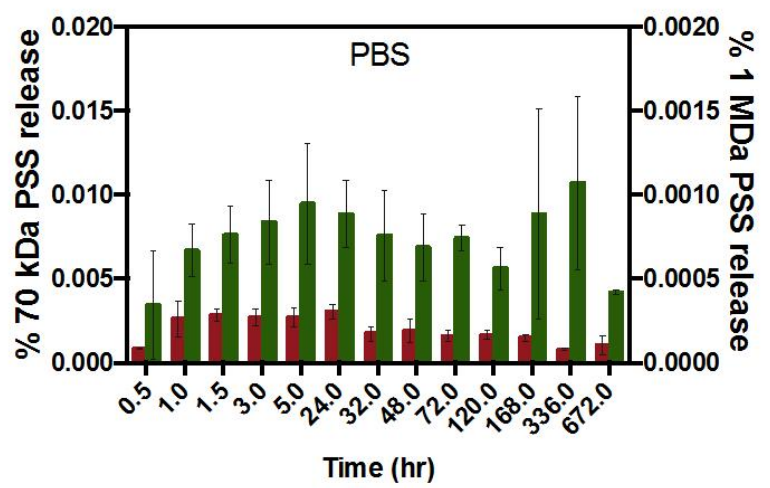

$70 \mathrm{kDa}$ PSS/PA in PBS
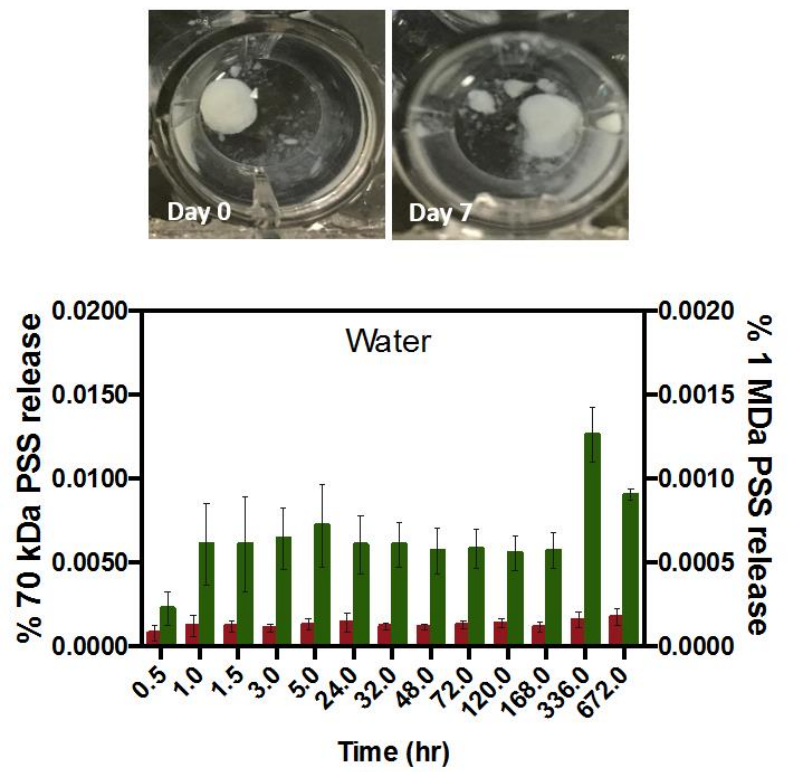

Figure 3. Stability of the hydrogels in water and PBS at $37^{\circ} \mathrm{C}$. (A) Comparison between $1 \mathrm{MDa}$ PSS/PA hydrogel with $70 \mathrm{kDa}$ PSS/PA (with disintegration by day 7 in PBS). (B) Graphs showing the PSS release from $1 \mathrm{MDa}$ PSS/PA (red bars) and $70 \mathrm{kDa}$ PSS/PA (green bars) hydrogels when incubated in water or PBS over 28 days.

Nanostructure and mineralization of the PSS/PA hydrogels. Yoreo et al. showed that a PSS matrix was able to induce the biomimetic nucleation of calcium carbonate minerals. ${ }^{18}$ Negatively charged groups in biomacromolecules, including carboxylic, phosphate and sulfate groups, play 
a crucial role in the nucleation of calcium-based minerals. ${ }^{18,38,39}$ In a similar way, we hypothesize that the presence of sulfonate groups in PSS/PA hydrogels could induce the nucleation of calcium phosphate mineral as precursor of hydroxyapatite. In order to test this hypothesis, hydrogels were first incubated in a simulated body fluid (SBF) for a period of 14 days. ${ }^{20,21}$ After 14 days incubation, samples were analysed by SEM and EDX, which showed the formation of calcium phosphate minerals over the hydrogel surface (Figure S6). However, SBF is a highly saturated medium, which does not resemble a controlled biomimetic mineralization. Thus, the hydrogels were incubated in culture medium over a period of 21 days (3-weeks, minimum time period for osteogenic differentiation).$^{40}$ Samples were incubated in four different culture media: DMEM without FBS (DMEM-FBS), DMEM with 10\% FBS (DMEM+FBS), osteogenic differentiation medium without FBS (ODM-FBS) and osteogenic differentiation medium with $10 \% \mathrm{FBS}(\mathrm{ODM}+\mathrm{FBS})$ at $37{ }^{\circ} \mathrm{C}$ and $5 \% \mathrm{CO}_{2}$ to replicate culture conditions. Mineral nucleation was detected by day 7 covering the hydrogels surface (Figure 4), but traces of calcium phosphate mineral were also observed in the hydrogel interior (Figure S7, SEM images of hydrogel cross-section). Minerals are spherical in morphology and deposited alongside the fibres; though it is also possible to get high concentrated areas of minerals (70 kDa PSS/PA, $\mathrm{D} 21)$. The ratio of $\mathrm{Ca} / \mathrm{P}$ changed with incubation time and is also different in the two hydrogel systems. In $1 \mathrm{MDa}$ PSS/PA hydrogels, the $\mathrm{Ca} / \mathrm{P}$ is close to hydroxyapatite $\left(\mathrm{Ca}_{10}\left(\mathrm{PO}_{4}\right)_{6}(\mathrm{OH})_{2}\right.$, 1.67) by day 7, whereas in $70 \mathrm{kDa}$ PSS/PA it takes up to 21 days to get a $\mathrm{Ca} / \mathrm{P}$ of 1.63 (Figure 4). PEDOT/PSS scaffolds without cells and incubated in proliferating medium (7 days) first, followed by 21 days in osteogenic medium, showed calcium deposition only after 28 days with no significant calcium accumulation by day $7 .{ }^{19}$ Calcium-phosphate nodules were seen and detected in 1 MDa PSS/PA gels after 7 days (Figure 4). The nanofiber structure of the PSS/PA 
gels may provide a more biomimetic template for hydroxyapatite mineralization.

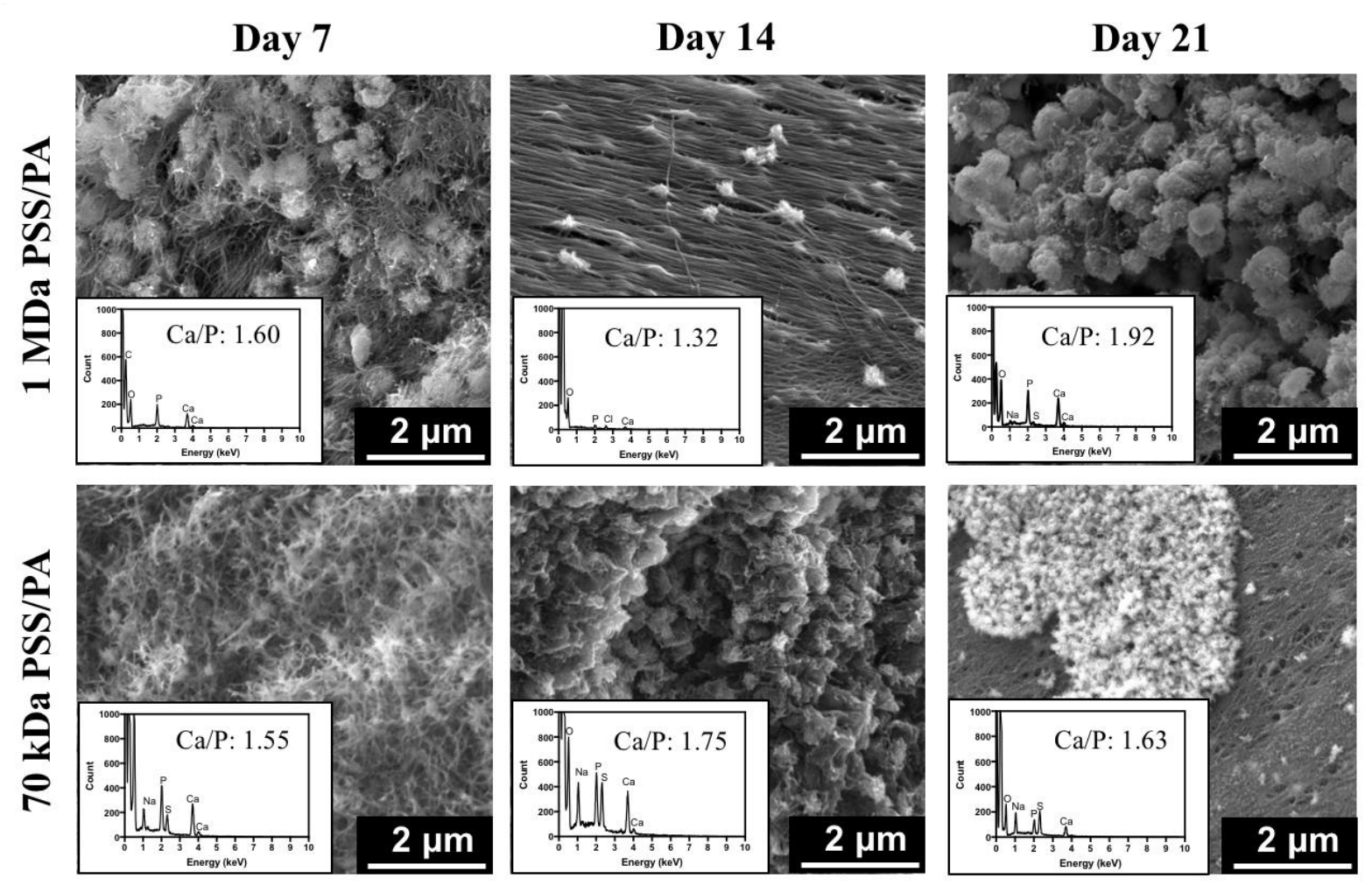

Figure 4. SEM images of mineralized hydrogels (1 MDa PSS/PA and $70 \mathrm{kDa}$ PSS/PA) incubated in DMEM-FBS medium at different incubation periods.

The effect of serum and osteogenic inducers in the medium on the mineralization of the gels was also investigated and Figure 5 summarises the data from these studies. Osteogenic medium contains $\beta$-glycerophosphate, an organic phosphate that can be cleaved by alkaline phosphatase (ALP) enzyme secreted by osteoblast cells, into free phosphate ions necessary for hydroxyapatite mineralization. The time-dependent formation of $\mathrm{PO}_{3}{ }^{2-}$ by ALP is expected to prevent rapid and uncontrolled mineral precipitation in solution. ${ }^{41}$ Once phosphates are cleaved, they can be incorporated in the calcium-nucleated PSS/PA nanofibers. The $\mathrm{Ca} / \mathrm{P}$ ratios of the mineral formed on $1 \mathrm{MDa}$ PSS/PA hydrogels incubated in basal medium with and without FBS (DMEM-FBS 
and DMEM+FBS) is close to tetra calcium phosphate (TTCP, $\left.\mathrm{Ca}_{4}\left(\mathrm{PO}_{4}\right)_{2} \mathrm{O}\right)$ with higher calcium content compared to the osteogenic media (ODM-FBS and ODM+FBS), which are calciumdeficient hydroxyapatite. This indicates that minerals with different resorbability can be formed on these gels depending on the mineralizing medium. Furthermore, these studies were performed without cells, which are expected to play a role in the mineralization process, by secreting ALP, while here the release of phosphate depends on the ALP present in FBS.
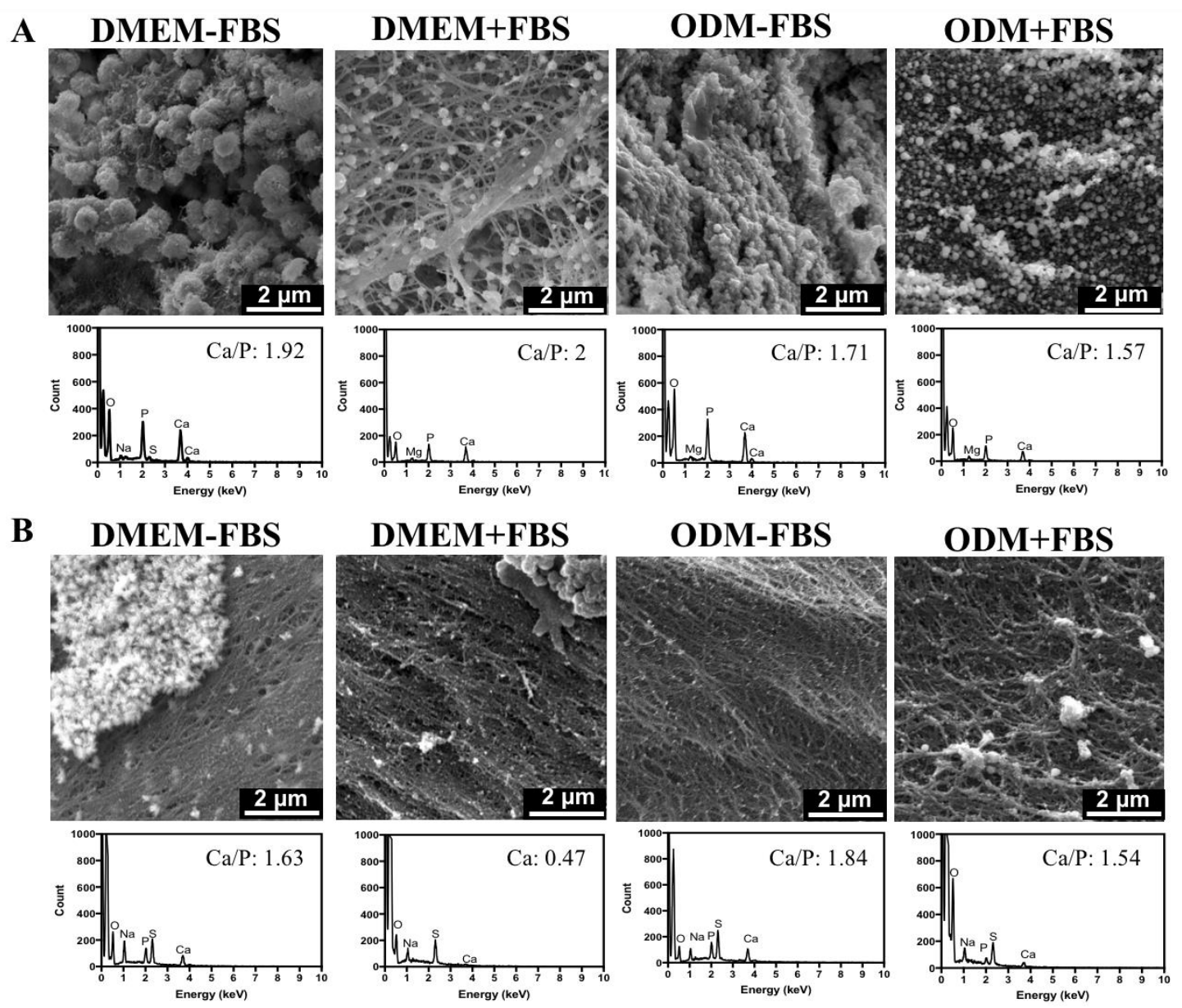

Figure 5. Mineralization of hydrogels in four different media (DMEM-FBS, DMEM+FBS, ODM-FBS and ODM+FBS) after 21 days of incubation shown by SEM micrographs and EDX spectra; (A) 1 MDa PSS/PA, (B) $70 \mathrm{kDa}$ PSS/PA.

The storage modulus of the gels after mineralization in the different media tended to increase, 
but differences were not statistically significant for most of the samples tested (Figure S8). To further characterize the minerals formed on the hydrogels, samples were heated up to $700{ }^{\circ} \mathrm{C}$ to completely burn the organic phase (peptide and polymer components). The remaining inorganic component (mineral, 4.5\%, Figure S9) was analysed by FTIR (Figure S10). Several bands corresponding to amines in the peptide's structure can be assigned in the spectrum of the nonmineralized hydrogel before heating, including amide I $\left(1635-1670 \mathrm{~cm}^{-1}\right)$, amide II $\left(1545 \mathrm{~cm}^{-1}\right)$ and amide III $\left(1400,1445 \mathrm{~cm}^{-1}\right)$. Moreover, the characteristic bands of $\mathrm{SO}_{3}{ }^{-}$are visible with a slight shift from 1187 to $1162 \mathrm{~cm}^{-1}$ and from 1043 to $1033 \mathrm{~cm}^{-1}$ corresponding to the asymmetric and symmetric stretching vibrations, respectively. ${ }^{42}$ The styrene ring of PSS overlapped with amide I band of PA hence giving an intense peak at $1613 \mathrm{~cm}^{-1}$. In the heated samples, the bands corresponding to the peptide disappeared and the bands associated with minerals are more visible, such as $\mathrm{HPO}_{4}{ }^{2-}\left(1090-1100 \mathrm{~cm}^{-1}\right), v_{3} \mathrm{PO}_{4}{ }^{3-}\left(1045,603\right.$, and $\left.570 \mathrm{~cm}^{-1}\right)$, and $v_{1} \mathrm{PO}_{4}{ }^{3-}(960$ $\left.\mathrm{cm}^{-1}\right) \cdot{ }^{43}$ However, the heating of samples above $600{ }^{\circ} \mathrm{C}$ can convert amorphous calcium phosphate into poorly crystallized apatite.

Based on the mechanical properties and mineralization capacity of the PSS/PA hydrogels, 1 MDa PSS/PA hydrogels were selected for further studies considering their greater stability and stiffness and faster mineralization capability (7 days).

Protein loading and release. Binding of GFs to the ECM takes place through different forms. One of the most prominent form is through electrostatic interactions with sulfated GAGs. ${ }^{44}$ Most GFs, such as basal fibroblast growth factor (bFGF, also known as fibroblast growth factor-2, FGF-2) and BMPs (bone morphogenetic proteins) are basic proteins having net positive charges. ${ }^{45}$ Considering the role of sulfate groups in GF binding, PSS/PA hydrogels could also 
serve as depots to store basic proteins and control their release for cell activation.

Two model proteins of different charges and sizes were chosen to study the ability of the PSS/PA gels for protein retention and release. Bovine serum albumin (BSA) is negatively charged at physiological $\mathrm{pH}(\mathrm{pI}=5.4)$ and has a size of $M_{w}: 67 \mathrm{kDa}^{46}$. Based on its negative charge, the protein was incorporated in the hydrogel by mixing it first with PSS solution (to avoid interaction with positive PA) and then assembled with PA. As positively charged protein, lysozyme $(\mathrm{pI}=11.4)$ with a size of $14 \mathrm{kDa}^{46}$ was used and first mixed with PA before selfassembly with PSS. Because self-assembly (gelation) occurs within 5 minutes at physiological conditions, the proteins can be entrapped inside the hydrogel without compromising their structure. To confirm the efficient incorporation of the proteins in the hydrogels, both proteins were labelled with fluorescent dyes to allow their visualization and distribution in the hydrogel by confocal microscopy and monitoring their release by fluorescence spectroscopy.

The possibility of loading multiple proteins in the PSS/PA gels was first investigated. Proteins were labelled with different fluorophores and their distribution in the hydrogel visualized by confocal microscopy (Figure 6). Green fluorescence (BSA-FITC) is observed in the form of nanofibers, indicating preferential interaction with PA, while the red fluorescence (lysozymerhodamine) appears mostly as clumps (potential interaction with PSS). EDX mapping of sulfur (Figure S5) shows a uniform distribution of sulfonic groups on the hydrogel. 

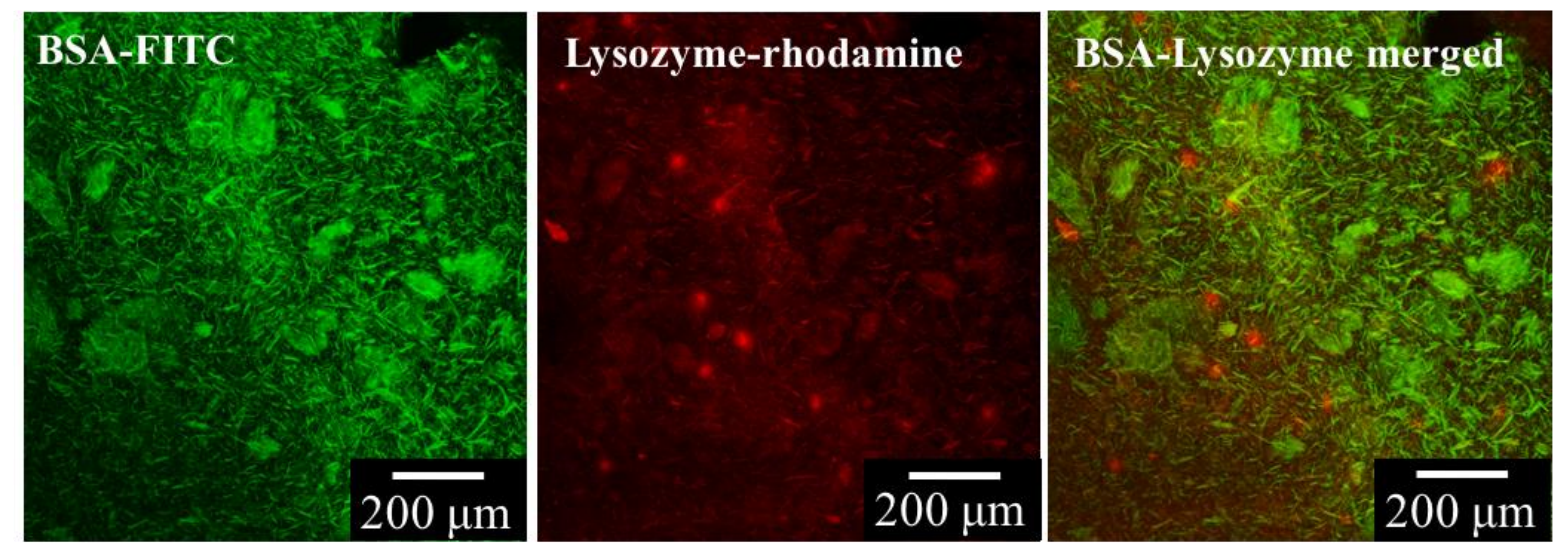

Figure 6. Confocal microscopy images of $1 \mathrm{MDa}$ PSS/PA hydrogels loaded with both BSA-FITC and lysozyme-rhodamine B.

To study the protein release, BSA and lysozyme were labelled with same fluorophore to eliminate the potential effect of fluorophore on the release pattern. In the first 24 hours of incubation, PSS/PA hydrogels released only 5\% of BSA reaching $11 \%$ after 30 days (Figure 7A,B). On the contrary, the amount of lysozyme released was higher, with 38\% released after 30 days. The diffusion of proteins through hydrogels can be controlled through the physical (mesh size) and/or the chemical (affinity) characteristics of the hydrogel. ${ }^{47}$ Protein (e.g. BSA) release from hydrogels typically occurs within 1-3 weeks depending on the type of hydrogel and crosslinking density ${ }^{48,49}$, even from sulfated HA hydrogels ${ }^{7}$, indicating low protein retention. Both components of the PSS/PA gel are charged (Figure S2) providing binding sites for proteins through electrostatic interactions. Lysozyme is smaller in size compared to BSA and SEM images of PSS/PA hydrogels (Figure S5) show a very dense network of nanofibers. Considering similar affinity of the proteins for the gel components, release is expected to be controlled mainly by diffusion. The higher amount of lysozyme released compared to BSA is confirmed by the confocal microscopy images of the gels taken after the release experiment (Figure S11-A) 
showing less fluorescence in the lysozyme-FITC loaded gels after 30 days. The slow release of BSA is further confirmed by the strong fluorescence exhibited by the gels loaded with BSAFITC after the release study and indicates strong interactions with gel components, probably with PA nanofibers. The effect of electrostatic interactions between proteins and self-assembling peptide hydrogels of high charge density was shown to modulate their release patterns. ${ }^{50}$ Minimal protein release (7\% over 28 days) was observed when unlabelled lactoferrin (77 kDa, pI $=8.4-9.0$, positively charged at $\mathrm{pH}$ 7.4) was incorporated into peptide gels bearing a negative charge, while negatively charged or neutral proteins were completely released over 5 days. Appel and co-workers reported extended BSA release up to 160 days from neutral supramolecular polymer gels, compared to lysozyme (40 days). The hydrogels were formed through host-guest interactions of poly(vinyl alcohol) modified with viologen (first guest) and the macrocyclic host cucurbit[8]uril and hydroxyethyl cellulose functionalized with a naphthyl moiety (second guest). ${ }^{51}$ For this hydrogel system, protein release is mainly controlled by the size of the protein and hydrogel concentration that determines the mesh size. With respect to GFs, incorporation and controlled release of recombinant FGF-2 $(\mathrm{Mw}=17.2 \mathrm{kDa}, \mathrm{pI}=9.7)^{14}$ has been described using heparin-containing carriers. For example, self-assembling heparin/PA (2/3 wt.\%) gels showed the ability to retard the release of FGF-2 from 100\% in control gels (without heparin) to $57.1 \%$ after 10 days and this delayed release has been reported for other selfassembling heparin/peptide ${ }^{11}$ and heparin-containing ${ }^{9,49}$ hydrogels. Considering that both lysozyme and FGF-2 are basic proteins with similar Mw, one can assume similar release of FGF2 from PSS/PA gels. Protein release results reveal the potential PSS/PA hydrogels for the continuous delivery of GFs or other proteins (e.g. antibodies) for considerable periods of time (long-acting release) to achieve robust therapies. 
A
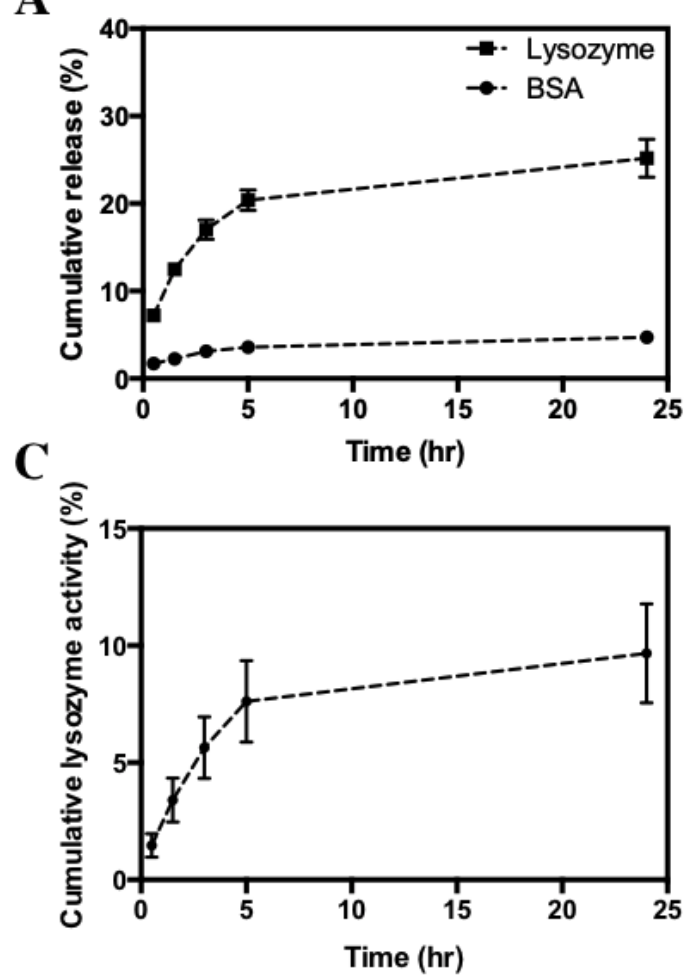

B
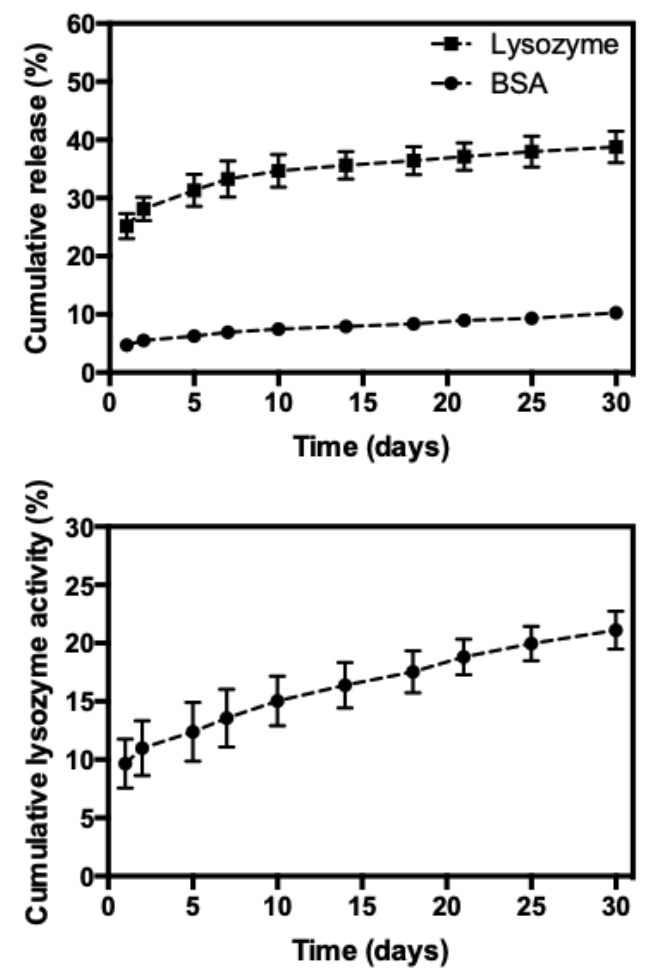

Figure 7. Cumulative release (mean $\pm \mathrm{SD}$ ) of BSA-FITC and lysozyme-FITC loaded in 1 MDa PSS/PA hydrogels at early time points (A, $24 \mathrm{~h}$ ) and for extended periods of time (B, 30 days). Cumulative lysozyme activity release (mean $\pm \mathrm{SD}$ ) from the hydrogels within the first $24 \mathrm{~h}(\mathrm{C})$ and over a month (D).

The ability of the PSS/PA gels to maintain the bioactivity of entrapped proteins was assessed by measuring the activity of lysozyme released from the gel (Figure 7-C, D). Increasing enzyme activity is observed as function of time, reaching $20 \%$ of initial activity after 30 days. Considering similar amounts of enzyme released (as measured for the lysozyme-FITC), a 50\% loss in the enzyme activity is estimated (Figure S11-B). However, when lysozyme is incubated in buffer only, it loses $80 \%$ of its initial activity after 14 days, similar to what was found by Appel, ${ }^{51}$ and indicates the protective effect of PSS/PA gel against enzyme deactivation.

Cell Viability. Cytotoxicity of the hydrogels was assessed with human bone marrow-derived 
mesenchymal stem cells (hMSCs). hMSCs were encapsulated in the hydrogels without or with the cell-adhesive sequence RGDS: PSS/PA hydrogel and PSS/PA-RGDS hydrogel (PSS/PA hydrogel containing 10\% of RGDS-containing PA, Figure S1-D). Incorporation of 10\% of PARGDS in the hydrogel formulation is aimed at promoting cell adhesion. Characterization of the mechanical properties of the resulting hydrogels did not show significant differences compared to plain gels (without 10\% of PA-RGDS, Figure S12).
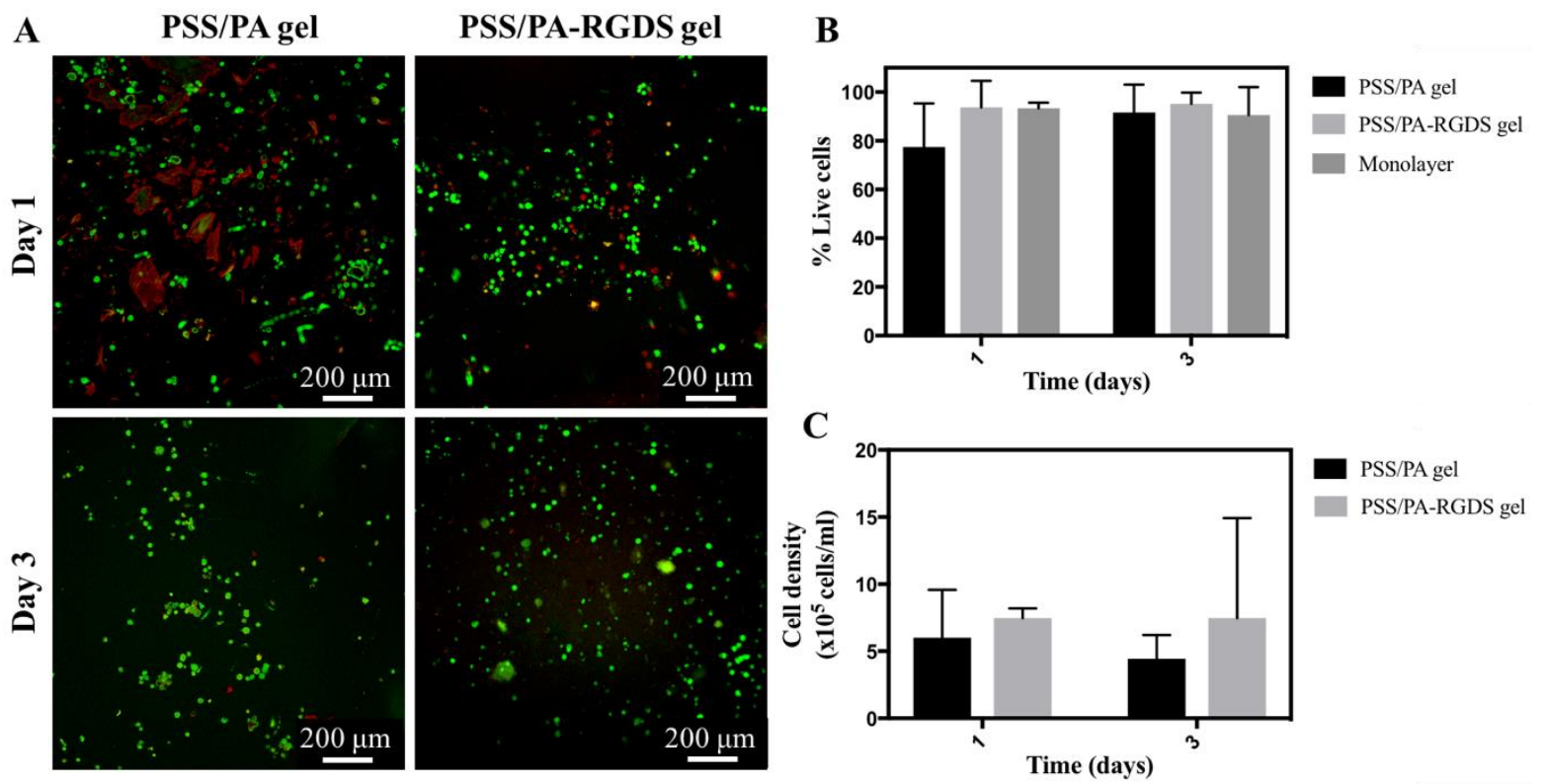

Figure 8. Viability of hMSCs encapsulated in 1 MDa PSS/PA hydrogels, with or without RGDS, for 1 and 3 days. (A) Confocal images of calcein-stained live cells and ethidium homodimer-stained dead cells; (B) Cell viability in the hydrogels compared to 2D culture. (C) Cell density in the hydrogels remained constant from day 1 to day 3 . (No significant difference between the groups)

Figure 8-A illustrates the distribution and morphology of the cells inside the hydrogels, as well as the overall viability, with live cells stained green and dead stained red (hydrogels showed auto-fluorescent in the red channel, hence the red background in the images). The viability increased slightly in both hydrogels over 3 days of culture compared to 2D culture (Figure 8-B), 
but statistical analysis showed no significant difference between the groups. This result confirmed that the gelation time (without DMEM) did not affect the cell viability and the hydrogel fabrication method is compatible for the encapsulation of cells (Figure 8-C). Cells appear round which is typically seen when encapsulated in hydrogels. ${ }^{48}$ The interaction of cells with the hydrogel nanofibers was also analysed by SEM (Figure 9). Cells are initially entrapped inside the dense nanofibrous structure of the gels, exhibiting round-shaped morphology even after 3 days of culture. However, in both PSS/PA and PSS/PA-RGDS gels, few cells were found with spread morphology. Similar findings were previously observed when culturing human dermal fibroblasts within self-assembled peptide capsules. By changing the nanofiber density, fibroblasts could recover their typical extended morphology. ${ }^{23}$ Matrix stiffness increases with matrix density and PSS/PA hydrogels with lower stiffness can be formed (Figure S3) and used to test the effect on cell morphology and differentiation. Taken together, the positive cell viability results and SEM analysis suggest that PSS/PA hydrogel can provide a biomimetic 3D environment for growing stem cells and studying their differentiation into different lineages. 

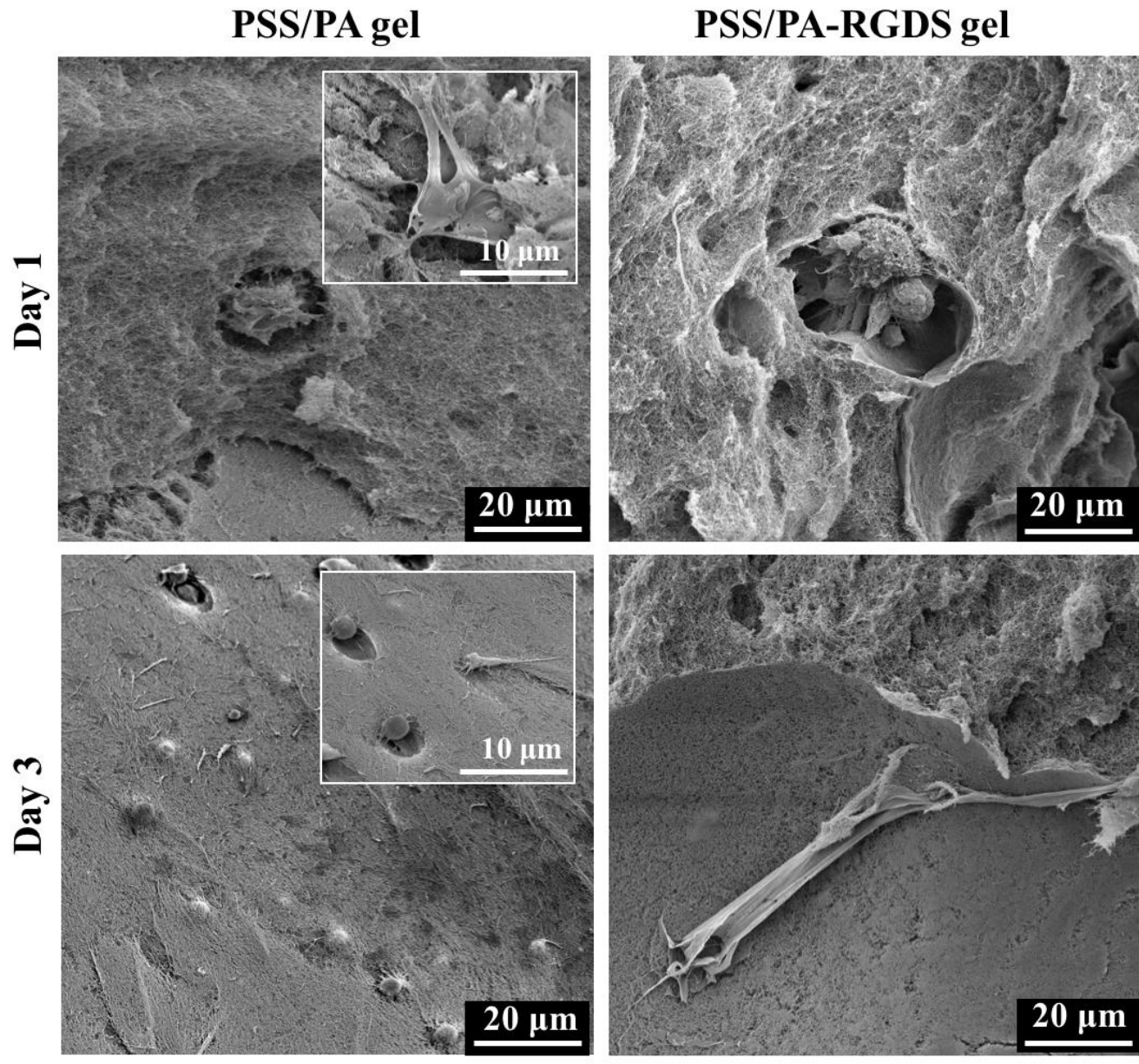

Figure 9. SEM micrographs of $1 \mathrm{MDa}$ PSS/PA hydrogels showing cells embedded in the dense nanofiber network at day 1 and their spreading at day 3 . 


\section{Conclusions}

Self-assembly of a known polyelectrolyte (PSS) with a PA of opposite charge in physiological conditions resulted in self-supporting stable hydrogels. The obtained hydrogels have nanofibrous structure and mechanical properties of stiff materials, which can be tuned by varying the concentration of individual components. The negative sulfonate groups of PSS provided nucleation points for calcium phosphate deposition. Depending on the mineralization medium used, different types of calcium phosphate mineral were formed. These hydrogels also showed the ability to retain and control the release of charged proteins, while preventing their rapid deactivation. Although preliminary, the positive results from cell culture studies suggest the potential of the PSS/PA hydrogels as 3D environments for cell differentiation either in vitro or in vivo. 
Supporting Information Available

The following files are available free of charge.

Figure S1: Characterization of peptide amphiphiles used this study

Figure S2: Zeta $(\zeta)$ potential of PA and PSS solutions

Figure S3: Storage modulus (G') PSS/PA hydrogels in function of their composition

Figure S4: Ratio of G', to G' $(\tan (\delta))$ of PSS/PA hydrogels

Figure S5: SEM/EDX analysis of PSS/PA hydrogels

Figure S6: SEM/EDX of SBF-incubated hydrogels

Figure S7: SEM images of hydrogel cross-sections after incubation in DMEM-FBS

Figure S8: Storage modulus (G') of PSS/PA hydrogels after mineralization

Figure S9: TGA analysis of PSS/PA hydrogels after incubation in mineralization medium

Figure S10: FTIR spectra of the hydrogels before and after burning

Figure S11: Confocal microscopy images of PSS/PA hydrogels loaded with labelled proteins before and after the release experiments; comparison between protein release and activity for lysozyme; decay of lysozyme activity over time at $37^{\circ} \mathrm{C}$ when free in solution.

Figure S12: Mechanical characterization of 1 MDa PSS/PA-RGDS hydrogel

\section{ACKNOWLEDGMENT}

We thank Mr Lazar Kirov, an undergraduate student at the School of Engineering and Materials

Science for measuring the viscosity of PSS and HA solutions. We thank the financial support from The Royal Society (Research Grant RSGIR1\180005).

\section{AUTHOR INFORMATION}

\section{Corresponding Author}

*E-mail: h.azevedo@qmul.ac.uk 


\section{REFERENCES}

(1) Wang, X.; Ding, B.; Li, B. Biomimetic Electrospun Nanofibrous Structures for Tissue Engineering. $\quad$ Mater. $\quad$ today $2013, \quad 16 \quad$ 229-241. https://doi.org/10.1016/j.mattod.2013.06.005.

(2) Hartgerink, J. D.; Beniash, E.; Stupp, S. I. Self-Assembly and Mineralization of PeptideAmphiphile Nanofibers. Science (80-. ). 2001, 294 (5547), 1684-1688. https://doi.org/10.1126/science.1063187.

(3) Mather, B. D.; Viswanathan, K.; Miller, K. M.; Long, T. E. Michael Addition Reactions in Macromolecular Design for Emerging Technologies. Prog. Polym. Sci. 2006, 31 (5), 487531. https://doi.org/10.1016/j.progpolymsci.2006.03.001.

(4) Pérez, C. M. R.; Stephanopoulos, N.; Sur, S.; Lee, S. S.; Newcomb, C.; Stupp, S. I. The Powerful Functions of Peptide-Based Bioactive Matrices for Regenerative Medicine. Ann. Biomed. Eng. 2015, 43 (3), 501-514. https://doi.org/10.1007/s10439-014-1166-6.

(5) Azevedo, H. S.; Pashkuleva, I. Biomimetic Supramolecular Designs for the Controlled Release of Growth Factors in Bone Regeneration. Adv. Drug Deliv. Rev. 2015, 94, 63-76. https://doi.org/10.1016/j.addr.2015.08.003.

(6) Mhanna, R.; Becher, J.; Schnabelrauch, M.; Reis, R. L.; Pashkuleva, I. Sulfated Alginate as a Mimic of Sulfated Glycosaminoglycans: Binding of Growth Factors and Effect on Stem Cell Behavior. Adv. Biosyst. 2017, $1 \quad$ (7), 1700043. https://doi.org/10.1002/adbi.201700043.

(7) Purcell, B. P.; Kim, I. L.; Chuo, V.; Guenin, T.; Dorsey, S. M.; Burdick, J. A. Incorporation of Sulfated Hyaluronic Acid Macromers into Degradable Hydrogel Scaffolds for Sustained Molecule Delivery. Biomater. Sci. 2014, 2 (5), 693-702. 
https://doi.org/10.1039/C3BM60227C.

(8) Feng, Q.; Lin, S.; Zhang, K.; Dong, C.; Wu, T.; Huang, H.; Yan, X.; Zhang, L.; Li, G.;

Bian, L. Sulfated Hyaluronic Acid Hydrogels with Retarded Degradation and Enhanced Growth Factor Retention Promote HMSC Chondrogenesis and Articular Cartilage Integrity with Reduced Hypertrophy. Acta Biomater. 2017, 53, 329-342. https://doi.org/10.1016/j.actbio.2017.02.015.

(9) Pike, D. B.; Cai, S.; Pomraning, K. R.; Firpo, M. A.; Fisher, R. J.; Shu, X. Z.; Prestwich, G. D.; Peattie, R. A. Heparin-Regulated Release of Growth Factors in Vitro and Angiogenic Response in Vivo to Implanted Hyaluronan Hydrogels Containing VEGF and BFGF. Biomaterials 2006, $27 \quad$ (30), 5242-5251. https://doi.org/10.1016/j.biomaterials.2006.05.018.

(10) Rajangam, K.; Behanna, H. A.; Hui, M. J.; Han, X.; Hulvat, J. F.; Lomasney, J. W.; Stupp, S. I. Heparin Binding Nanostructures to Promote Growth of Blood Vessels. Nano Lett. 2006, 6 (9), 2086-2090. https://doi.org/10.1021/n10613555.

(11) Galler, K. M.; Hartgerink, J. D.; Cavender, A. C.; Schmalz, G.; D’Souza, R. N. A Customized Self-Assembling Peptide Hydrogel for Dental Pulp Tissue Engineering. Tissue Eng. Part A 2011, 18 (1-2), 176-184. https://doi.org/10.1089/ten.tea.2011.0222.

(12) Fernández-Muiños, T.; Recha-Sancho, L.; López-Chicón, P.; Castells-Sala, C.; Mata, A.; Semino, C. E. Bimolecular Based Heparin and Self-Assembling Hydrogel for Tissue Engineering Applications. Acta Biomater. 2015, $16, \quad 35-48$. https://doi.org/10.1016/j.actbio.2015.01.008.

(13) Silva, C.; Carretero, A.; da Costa, D. S.; Reis, R. L.; Novoa-Carballal, R.; Pashkuleva, I. Design of Protein Delivery Systems by Mimicking Extracellular Mechanisms for 
Protection of Growth Factors. Acta Biomater. 2017, 63, 283-293. https://doi.org/10.1016/j.actbio.2017.08.042.

(14) Macdonald, M. L.; Rodriguez, N. M.; Shah, N. J.; Hammond, P. T. Characterization of Tunable FGF-2 Releasing Polyelectrolyte Multilayers. Biomacromolecules 2010, 11 (8), 2053-2059. https://doi.org/10.1021/bm100413w.

(15) Hendrikse, S. I. S.; Spaans, S.; Meijer, E. W.; Dankers, P. Y. W. Supramolecular Platform Stabilizing Growth Factors. Biomacromolecules 2018, 19, 2610-2617. https://doi.org/10.1021/acs.biomac.8b00219.

(16) Mammadov, R.; Mammadov, B.; Guler, M. O.; Tekinay, A. B. Growth Factor Binding on Heparin Mimetic Peptide Nanofibers. Biomacromolecules 2012, 13 (10), 3311-3319. https://doi.org/10.1021/bm3010897.

(17) Radvar, E.; Azevedo, H. S. Supramolecular Peptide/Polymer Hybrid Hydrogels for Biomedical Applications. Macromol. Biosci. $\quad$ 2018, 1800221. https://doi.org/10.1002/mabi.201800221.

(18) Smeets, P. J. M.; Cho, K. R.; Kempen, R. G. E.; Sommerdijk, N. A. J. M.; De Yoreo, J. J. Calcium Carbonate Nucleation Driven by Ion Binding in a Biomimetic Matrix Revealed by in Situ Electron Microscopy. Nat. Mater. 2015, 14 (4), 394-399. https://doi.org/10.1038/nmat4193.

(19) Guex, A. G.; Puetzer, J. L.; Armgarth, A.; Littmann, E.; Stavrinidou, E.; Giannelis, E. P.; Malliaras, G. G.; Stevens, M. M. Highly Porous Scaffolds of PEDOT: PSS for Bone Tissue Engineering. Acta Biomater. 2017, 62, 91-101. https://doi.org/10.1016/j.actbio.2017.08.045.

(20) Kokubo, T.; Takadama, H. How Useful Is SBF in Predicting in Vivo Bone Bioactivity? 
Biomaterials

2006,

27

$(15)$,

$2907-2915$.

https://doi.org/10.1016/j.biomaterials.2006.01.017.

(21) Kokubo, T. Design of Bioactive Bone Substitutes Based on Biomineralization Process. Mater. Sci. Eng. C 2005, 25 (2), 97-104. https://doi.org/10.1016/j.msec.2005.01.002.

(22) Bitton, R.; Chow, L. W.; Zha, R. H.; Velichko, Y. S.; Pashuck, E. T.; Stupp, S. I. Electrostatic Control of Structure in Self- Assembled Membranes. Small 2014, 10 (3), 500-505. https://doi.org/10.1002/smll.201300254.

(23) Ferreira, D. S.; Reis, R. L.; Azevedo, H. S. Peptide-Based Microcapsules Obtained by Self-Assembly and Microfluidics as Controlled Environments for Cell Culture. Soft Matter 2013, 9 (38), 9237-9248. https://doi.org/10.1039/C3SM51189H.

(24) Ferreira, D. S.; Marques, A. P.; Reis, R. L.; Azevedo, H. S. Hyaluronan and SelfAssembling Peptides as Building Blocks to Reconstruct the Extracellular Environment in Skin Tissue. Biomater. Sci. 2013, 1 (9), 952-964. https://doi.org/10.1039/C3BM60019J.

(25) Capito, R. M.; Azevedo, H. S.; Velichko, Y. S.; Mata, A.; Stupp, S. I. Self-Assembly of Large and Small Molecules into Hierarchically Ordered Sacs and Membranes. Science (80-. ). 2008, 319 (5871), 1812-1816. https://doi.org/10.1126/science.1154586.

(26) Itzhak-Cohen, R.; Nativ-Roth, E.; Levi-Kalisman, Y.; Josef, E.; Szleifer, I.; YerushalmiRozen, R. Nematic Ordering of SWNT in Meso-Structured Thin Liquid Films of Polystyrenesulfonate. $\quad$ Langmuir 2014, $30 \quad$ (49), $\quad$ 14963-14970. https://doi.org//10.1021/la503287q.

(27) Lapčík, L.; Lapcik, L.; De Smedt, S.; Demeester, J.; Chabrecek, P. Hyaluronan: Preparation, Structure, Properties, and Applications. Chem. Rev. 1998, 98 (8), 2663-2684. https://doi.org/10.1021/cr941199z. 
(28) Pashuck, E. T.; Cui, H.; Stupp, S. I. Tuning Supramolecular Rigidity of Peptide Fibers through Molecular Structure. J. Am. Chem. Soc. 2010, 132 (17), 6041-6046. https://doi.org/10.1021/ja908560n.

(29) Maslovskis, A.; Tirelli, N.; Saiani, A.; Miller, A. F. Peptide-PNIPAAm Conjugate Based Hydrogels: Synthesis and Characterisation. Soft Matter 2011, 7 (13), 6025-6033. https://doi.org/10.1039/C1SM05288H.

(30) Wang, L.; Hsu, H.-Y.; Li, X.; Xian, C. J. Effects of Frequency and Acceleration Amplitude on Osteoblast Mechanical Vibration Responses: A Finite Element Study. Biomed Res. Int. 2016, 2016, 16. https://doi.org/10.1155/2016/2735091.

(31) Goktas, M.; Cinar, G.; Orujalipoor, I.; Ide, S.; Tekinay, A. B.; Guler, M. O. SelfAssembled Peptide Amphiphile Nanofibers and PEG Composite Hydrogels as Tunable ECM Mimetic Microenvironment. Biomacromolecules 2015, 16 (4), 1247-1258. https://doi.org/10.1021/acs.biomac.5b00041.

(32) Levental, I.; Georges, P. C.; Janmey, P. A. Soft Biological Materials and Their Impact on Cell Function. Soft Matter 2007, 3 (3), 299-306. https://doi.org/10.1039/B610522J.

(33) Beniash, E.; Hartgerink, J. D.; Storrie, H.; Stendahl, J. C.; Stupp, S. I. Self-Assembling Peptide Amphiphile Nanofiber Matrices for Cell Entrapment. Acta Biomater. 2005, 1 (4), 387-397. https://doi.org/10.1016/j.actbio.2005.04.002.

(34) Greenfield, M. A.; Hoffman, J. R.; Olvera de la Cruz, M.; Stupp, S. I. Tunable Mechanics of Peptide Nanofiber Gels. Langmuir 2009, $26 \quad$ (5), 3641-3647. https://doi.org/10.1021/la9030969.

(35) Kumar, V. A.; Shi, S.; Wang, B. K.; Li, I.-C.; Jalan, A. A.; Sarkar, B.; Wickremasinghe, N. C.; Hartgerink, J. D. Drug-Triggered and Cross-Linked Self-Assembling Nanofibrous 
Hydrogels. J. Am. Chem. Soc. 2015, 137 (14), 4823-4830. https://doi.org/10.1021/jacs.5b01549.

(36) Miles, D. E.; Mitchell, E. A.; Kapur, N.; Beales, P. A.; Wilcox, R. K. Peptide: Glycosaminoglycan Hybrid Hydrogels as an Injectable Intervention for Spinal Disc Degeneration. J. Mater. Chem. B 2016, 4 (19), 3225-3231. https://doi.org/10.1039/C6TB00121A.

(37) Li, R.; McRae, N. L.; McCulloch, D. R.; Boyd-Moss, M.; Barrow, C. J.; Nisbet, D. R.; Stupka, N.; Williams, R. J. Large and Small Assembly: Combining Functional Macromolecules with Small Peptides to Control the Morphology of Skeletal Muscle Progenitor Cells. Biomacromolecules 2018, $19 \quad$ (3), 825-837. https://doi.org/10.1021/acs.biomac.7b01632.

(38) Addadi, L.; Moradian, J.; Shay, E.; Maroudas, N. G.; Weiner, S. A Chemical Model for the Cooperation of Sulfates and Carboxylates in Calcite Crystal Nucleation: Relevance to Biomineralization. Proc. Natl. Acad. Sci. U. S. A. 1987, 84 (9), 2732-2736. https://doi.org/10.1180/0026461056950275.

(39) Ribeiro, S.; Radvar, E.; Shi, Y.; Borges, J.; Pirraco, R. P.; Leonor, I. B.; Mano, J. F.; Reis, R. L.; Mata, Á.; Azevedo, H. S. Nanostructured Interfacial Self-Assembled PeptidePolymer Membranes for Enhanced Mineralization and Cell Adhesion. Nanoscale 2017, 9 (36), 13670-13682. https://doi.org/10.1039/c7nr03410e.

(40) Langenbach, F.; Handschel, J. Effects of Dexamethasone, Ascorbic Acid and $\beta$ Glycerophosphate on the Osteogenic Differentiation of Stem Cells in Vitro. Stem Cell Res. Ther. 2013, 4 (5), 117. https://doi.org/10.1186/scrt328.

(41) Spoerke, E. D.; Anthony, S. G.; Stupp, S. I. Enzyme Directed Templating of Artificial 
Bone Mineral. $\quad A d v . \quad$ Mater. 2009, $21 \quad$ 425-430. https://doi.org/10.1002/adma.200802242.

(42) M’Bareck, C. O.; Nguyen, Q. T.; Metayer, M.; Saiter, J. M.; Garda, M. R. Poly (Acrylic Acid) and Poly (Sodium Styrenesulfonate) Compatibility by Fourier Transform Infrared and Differential Scanning Calorimetry. Polymer (Guildf). 2004, 45 (12), 4181-4187. https://doi.org/10.1016/j.polymer.2004.03.044.

(43) Sargeant, T. D.; Aparicio, C.; Goldberger, J. E.; Cui, H.; Stupp, S. I. Mineralization of Peptide Amphiphile Nanofibers and Its Effect on the Differentiation of Human Mesenchymal Stem Cells. Acta Biomater. 2012, $8 \quad$ (7), 2456-2465. https://doi.org/10.1016/j.actbio.2012.03.026.

(44) Rawat, M.; Gama, C. I.; Matson, J. B.; Hsieh-Wilson, L. C. Neuroactive Chondroitin Sulfate Glycomimetics. J. Am. Chem. Soc. 2008, 130 (10), 2959-2961. https://doi.org/10.1021/ja709993p.

(45) Schultz, G. S.; Wysocki, A. Interactions between Extracellular Matrix and Growth Factors in Wound Healing. Wound Repair Regen. 2009, 17 (2), 153-162. https://doi.org/10.1111/j.1524-475X.2009.00466.x.

(46) Loh, X. J.; Nguyen, V. P. N.; Kuo, N.; Li, J. Encapsulation of Basic Fibroblast Growth Factor in Thermogelling Copolymers Preserves Its Bioactivity. J. Mater. Chem. 2011, 21 (7), 2246-2254. https://doi.org/10.1039/C0JM03051A.

(47) Li, J.; Mooney, D. J. Designing Hydrogels for Controlled Drug Delivery. Nat. Rev. Mater. 2016, 1 (12), 16071. https://doi.org/10.1038/natrevmats.2016.71.

(48) Rosales, A. M.; Rodell, C. B.; Chen, M. H.; Morrow, M. G.; Anseth, K. S.; Burdick, J. A. Reversible Control of Network Properties in Azobenzene-Containing Hyaluronic Acid- 
Based Hydrogels. Bioconjug. Chem. 2018, 29 (4), 905-913. https://doi.org/10.1021/acs.bioconjchem.7b00802.

(49) Cai, S.; Liu, Y.; Shu, X. Z.; Prestwich, G. D. Injectable Glycosaminoglycan Hydrogels for Controlled Release of Human Basic Fibroblast Growth Factor. Biomaterials 2005, 26 (30), 6054-6067. https://doi.org/10.1016/j.biomaterials.2005.03.012.

(50) Nagy-Smith, K.; Yamada, Y.; Schneider, J. P. Protein Release from Highly Charged Peptide Hydrogel Networks. J. Mater. Chem. B 2016, 4 (11), 1999-2007. https://doi.org/10.1039/C5TB02137E.

(51) Appel, E. A.; Loh, X. J.; Jones, S. T.; Dreiss, C. A.; Scherman, O. A. Sustained Release of Proteins from High Water Content Supramolecular Polymer Hydrogels. Biomaterials 2012, 33 (18), 4646-4652. https://doi.org/10.1016/j.biomaterials.2012.02.030. 
For Table of Contents Use Only

Supramolecular nano-fibrous peptide/polymer hydrogels for the multiplexing of bioactive signals

Elham Radvar and Helena S. Azevedo

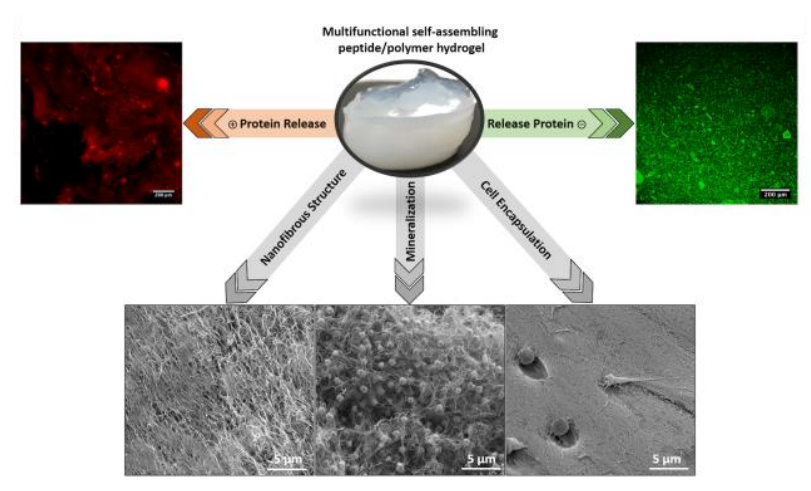

